\title{
A study of Craniospinal Imaging in Patients with Anorectal Malformation
}

\author{
Chanchlani R $\mathbf{R}^{1}$, Agravat $\mathrm{M}^{2}$, Agarwal $\mathrm{V}^{3}$, Agarwal $\mathrm{R}^{4}$, Rathore $\mathrm{S}^{5}$ \\ ${ }^{1}$ Dr Roshan Chanchlani, Associate professor, Department of Surgery Chirayu Medical College Bhopal, India. ${ }^{2}$ Dr Mehul Agravat, \\ Associate Professor, Department of Surgery, Chirayu Medical College, Bhopal. ${ }^{3}$ Dr Vikesh Agarwal, Associate professor \\ Department of Paediatric. Surgery NSCB Medical college Jabalpur, ${ }^{4}$ Dr Rekha Agarwal, Associate professor Department of \\ Radiology NSCB Medical college Jabalpur. ${ }^{5}$ Dr Sunil Rathore, RSO Department of Surgery NSCB Medical college Jabalpur, \\ India
}

Address for correspondence: Dr. Roshan Chanchlani, Email: roshanchanchlani@gmail.com

\begin{abstract}
Introduction: Anorectal malformations are commonly associated with craniospinal abnormalities like hydrocephalus, tethered cord syndrome, occult spinal dysraphism, syringomyelia, meningomyelocele and Arnold Chiari malformation. Aim of our study was to identify the incidence of craniospinal anomalies in patients with anorectal malformation and to analyse utility of Ultrasound and MRI as a screening tool in these patients to detect such anomalies. Material and Method: 52 infants male and female of anorectal malformation were included. All underwent ultrasonography of brain and spinal cord and 27 patients underwent MRI to detect craniospinal anomalies. Result: Out of 52 cases 38(73.07\%) were males and 14(26.93 \%) were females. High type ARM (34.61\%) and Vestibular fistulas(19.23\%) were most common type in male \& female child respectively. On ultrasonography in this series no craniospinal abnormality was found. On ultrasonography subarachnoid space was normal in all cases and central canal diameter was found $<1 \mathrm{~cm}$ in all cases. No abnormalities were detected in posterior fossa like cistermagna dilatation, dilated ventricles, Chiari Malformation. MRI spine was done 27 patients with high and low type malformation, but no abnormality was detected. Conclusion: Craniospinal anomaly and tethered cord are not frequently found in patients with anorectal malformation, in Northern Indian Population. As no association was found between craniospinal anomalies and anorectal malformation in the present study, the use of Ultrasonography and MRI as a screening tool is not recommended unless clinically indicated.
\end{abstract}

Key Words: Anorectal malformation, Arnold Chiari malformation, craniospinal abnormalities

\section{Introduction}

Anorectal malformation is associated with maldevelopment of neighbouring structures arising from caudal cell mass. Various craniospinal abnormalities in theses patients are often unnoticed until manifest. The detrimental consequences of untreated craniospinal diseases are often irreversible.Various craniospinal abnormalities associated with anorectal malformation are hydrocephalus, tethered cord syndrome, occult spinal dysraphism, syringomyelia, Meningomyelocoele and Arnold Chiari malformation. $\mathrm{T}$ 'hese anomalies are seen in as much as $46.5 \%$ neonates with anorectal malformation [1]. Apart from ultrasonography, MRI is a standard diagnostic tool for assessing craniospinal abnormalities but limitation of MRI in developing countries are poor cost effectiveness and need of anesthesia to perform the procedure in children. So,

Manuscript received: $26^{\text {th }}$ Jan 2014

Reviewed: $29^{\text {th }}$ Jan 2014

Author Corrected: $15^{\text {th }}$ Feb 2014

Accepted for Publication: $18^{\text {th }}$ Mar 2014
Ultrasonography plays role in screening for these craniospinal abnormalities in anorectal malformations [2]. This utilizes the advantages of ultrasound like cost effectiveness, easy availability, high resolution techniques and good soft tissue window in infants for visualization of brain and spinal cord. There are very few reports describing the incidence of such anomalies in Northern India.

Thus there is need of a study to evaluate the incidence of such anomalies and henceforth subsequent role of routine screening test for detection of craniospinal abnormalities associated with anorectal malformation.

\section{Material and methods}

This is a prospective study, conducted in Department of Surgery and Department of Radio diagnosis, in tertiary care hospital from January 2012 to December 2013. 
Inclusion criteria: 52 infants, male and female, presenting with all varieties of anorectal malformation were included in this study.

Exclusion criteria-The patients beyond infancy were excluded from the study (As soft tissue window is obliterated with ossification).

\section{Method}

Sonography is done by a consultant sonologist having experience in pediatric radiology and is done by high frequency probes [10 MHZ] under oral sedation with syrup promethazine/trichlorophos, the dose was given according to weight of child. Brain structures like lateral ventricles, third ventricles, corpus callosum, thalamus, posterior fossa and their related anomalies like hydrocephalus, Chiari malformation, corpus callosal agenesis, meningocele, encephelocele etc were seen. Spinal cord and vertebral column structures on ultrasonography were also analysed. Spinal cord, anterior and posterior subarachnoid spaces were seen as a hypo echoic structures and transverse process of spine, ribs are seen as hyper echoic structures. All images were saved as electronic documents and interpretation were done collectively by same sonologist. Plain X-ray anteroposterior and lateral views were performed in all patients to identify bony sacral anomalies. MRI spine was done in 27 consecutive patients, rest failed to undergo MRI due to financial restraints. Ethical committee approval was taken and statically analyses are done according to data collection and need of test on appropriate software with respect to identify the role of test as screening tool.

\section{Results}

Results are depicted in following tables.

Table 1: Distribution of cases according to sex

\begin{tabular}{|l|l|}
\hline Gender $[\mathbf{N}=\mathbf{5 2}]$ & No. of cases $\mathbf{( \% )}$ \\
\hline Male & $38(73.07 \%)$ \\
\hline Female & $14(26.93 \%)$ \\
\hline
\end{tabular}

The present study included 52 neonates with anorectal malformation. All neonates were from age one day to twelve months. Out of 52 cases 38(73.07\%) were males and 14(26.93\%) were females (Table 1)

Table 2: Distribution of cases according to type of ARM

\begin{tabular}{|l|l|}
\hline Type of ARM & No. of cases $\mathbf{N}=\mathbf{5 2}(\mathbf{\%})$ \\
\hline Male, High type ARM & $18(34.61 \%)$ \\
\hline Male, Intermediate type ARM & $6(11.53 \%)$ \\
\hline Male, Low type ARM & $14(26.92 \%)$ \\
\hline Female, Vestibular fistula & $10(19.23 \%)$ \\
\hline Cloaca & $4(7.69 \%)$ \\
\hline
\end{tabular}

Distribution of cases according to the type of anorectal malformation is shown in (Table2). As per table male high type ARM was most common type in almost one third of total patients

\section{Table 3: Distribution according to type of ARM and brain anomalies on USG}

\begin{tabular}{|l|l|l|l|}
\hline Type of ARM (N=52) & Corpus Callosum agenesis & Ventricular dilatation & Chiari Malformation \\
\hline Male, High type $[18]$ & $0[0 \%]$ & $0[0 \%]$ & $0[0 \%]$ \\
\hline Male, Intermediate type $[6]$ & $0[0 \%]$ & $0[0 \%]$ & $0[0 \%]$ \\
\hline Male, Low type[14] & $0[0 \%]$ & $0[0 \%]$ & $0[0 \%]$ \\
\hline Vestibular fistula[10] & $0[0 \%]$ & $0[0 \%]$ & $0[0 \%]$ \\
\hline Cloaca[4] & $0[0 \%]$ & $0[0 \%]$ & $0[0 \%]$ \\
\hline
\end{tabular}

Above table showing association of different brain anomalies (corpus callosum, parenchyma and ventricle related) found on ultrasonography in neonates with anorectal malformation. No abnormality was found in high type and as well as in low type. 
Table 4: Distribution of cases according to low lying cord and type of ARM

\begin{tabular}{|l|l|}
\hline Type of ARMN=52 & L1-L2 N (\%) \\
\hline Male, High type[18] & $2[11.11 \%]$ \\
\hline Male, Intermediate type[6] & $0[0 \%]$ \\
\hline Male, Low type [14] & $1[7.6 \%]$ \\
\hline Vestibular fistula [10] & $1[10 \%]$ \\
\hline Cloaca [4] & $0[0 \%]$ \\
\hline
\end{tabular}

Above table showing level of termination of spinal cord in patients with high and low type anorectal malformation. In patients with high type anorectal malformation, 3.57\% patient showing termination of spinal cord at T11-T12, 85.71\% showing at T12L1, 10.71\% showing at L1-L2. In low type, 8.33\% patients show termination at T11-T12, 87.5\% showing termination at T12-L1 and $4.16 \%$ showing at L1-L2 level.

\section{ARM and subarachnoid space and central canal diameter on USG Spine}

All neonates underwent ultrasonographic evaluation of spine for parameters like central canal diameter, subarachnoid space, termination of cord and for other significant abnormality is showing that on ultrasonography subarachnoid space is normal in all cases and central canal diameter is found $<1 \mathrm{~cm}$ in all 52 cases and no variation found between high type and low type anorectal malformation. No abnormality was detected in posterior fossa like cistermagna dilatation, dilated ventricles, Chiari Malformation etc.

\section{Distribution of cases according to abnormality detected on MRI spine}

MRI scan done in 27 patients. No abnormality was detected on MRI scanning.

\section{Discussion}

According to western literature craniospinal abnormalities especially spinal abnormalities are very common among patients with anorectal malformation; incidence is up to $46 \%$ [3-7]. In India it is up to $10 \%$ [8]. Some studies suggest that high resolution ultrasonography can detect craniospinal abnormalities efficiently but recently most of the studies suggest MRI as a routine investigation in patients with anorectal malformation because of high incidence of spinal abnormalities association with ARM [9]. In our series ultrasonography was performed in all cases, if altered or inconclusive; it was completed with Magnetic Resonance Image (MRI).

Among 52 patients, 18 patients had high type, 6 patients with intermediate type, 14 with low type, 10 with vestibular fistula, and 4 with cloaca. In this study No association was found in corpus callosum agenesis, brain parenchyma (Chiari malformation) and ventricles abnormality on ultrasonography of brain. This result is in contrast to western literature, which says the incidence to be $8.3 \%[10]$. In our study there is wide variation found in posterior cranial fossa diameter on ultrasonography of brain, it varied from $4.7 \mathrm{~cm}$ to $6.1 \mathrm{~cm}$. Patients of lesser age have less posterior cranial fossa diameter and vice a versa. The reason for this discripency may be age of neonates. Despite of this variation in posterior cranial fossa diameter, no brain abnormalies were detected. So we can say that posterior cranial fossa diameter is insignificant in relation to cranialspinal anomalies associated with anorectal malformation. In this study the dimension of central canal diameter is $<1 \mathrm{~cm}$ in all the patients and no abnormalities were detected in subarachnoid space. In our study in 5.7\% cases spinal cord terminates at $\mathrm{T} 11-\mathrm{T} 12$, in $86.5 \%$ cases spinal cord terminates at $\mathrm{T} 12-\mathrm{L} 1$, in $7.5 \%$ cases spinal cord terminates at L1-L2.the incidence of spinal cord termination is almost equal in both high and low variety and in accordance with the literature. In study of Suppiej A et al $33.8 \%$ incidence of tethered cord in anorectal malformation was seen [11]. Taskinen $\mathrm{S}$ et al showed $13.3 \%$ incidence of tethered cord in ARM [3].

According to world literature the incidence of spinal cord anomalies is in the range of $10 \%-40 \%$ in anorectal malformation, but in our study the incidence was $0 \%$. As compared to other studies the incidence in our study is very contrast. In the study of Lisa $\mathrm{H}$. Lowe et al [12] and 
Blaicher W, Prayer D et al [13]. USG brain was taken as a screening tool. According to Beek FJA et al ultrasound of the spinal cord and spine has been advocated as a screening method for patients with anorectal malformation[14]. Low lying cord (ending at L2) was found in 3 patients $(7.6 \%)$, but had no sonological and MRI findings suggestive of Tethered cord were seen hence, this group needs a longer follow up to identify its importance.

\section{Conclusion}

Ultrasonography gives good anatomical details of cranial and spinal structures quite accurately during infantile period. In our study craniospinal anomaly and tethered cord are not frequently found in patients with anorectal malformation. Use of MRI along with USG adds no distinct advantage in craniospinal anomaly detection in patient with anorectal malformation. Decisions to go for craniospinal MRIs and USGs, routinely in patients with ARM should be preceded by evaluation of incidence in the proposed scenario and subject to positive clinical finding. Larger series for longer duration of follow up (especially for Tethered cord syndrome) are needed to further substantiate the fact.

\section{Funding: Nil}

\section{Conflict of interest: Nil}

Permission from IRB: Yes

\section{References}

1. H A Heij, Abnormal anatomy of the lumbosacral region imaged by magnetic resonance in children with anorectal malformations. J Arch Dis Child 1996;74(5):441-444

2. Lisa H. Lisa H. Lowe, Andrew J. Johanek and Charlotte W. Mooreet: Normal Anatomy, Imaging Pitfalls and Variations That May Simulate Disorders, Sonography of the Neonatal Spine. AJR 2007;18(8):733-738

3. Taskinen S, Valanne L, Rintala R: Effect of spinal abnormalities on the function of lower urinary tract in patients with anorectal malformation. $\mathrm{J}$ Urol 2002;168(3):1147-9
4. Sato S, Shirane R, Yoshimoto T: Evaluation of tethered cord syndrome associated with anorectal malformations. Discussion of, J Neurosurgery 1993;32(6):1027-8

5. Kim SM, Spinal dysraphism with anorectal malformation: Lumbosacral magnetic resonance imaging evaluation of 120 patients. J Pediatr Surg 2010;45(4):76976.

6. Marc A Levitt, Alberto Peña: Anorectal malformations. Orphanet J rare dis 2007;2:33

7. Amit Mittal, Associated anomalies with ARM. Indian J Pediatr 2004;(71) 509-514.

8. Uchida K, Inoue M, Matsubara T, Otake K, Koike Y: Evaluation and treatment for spinal cord tethering in patients with anorectal malformations. Eur J Pediatr Surg 2007;17(6):408-11

9. Scott W: Magnetic Resonance Imaging of the Brain and Spine, 2004; Volume 1, Atlas, 240-242.

110. L. Santiago Medina, Kimberly E. Applegate, C. Craig Blackmore L: Evidence-Based Imaging in Pediatrics: Optimizing Imaging in Pediatrics. 2009 Edition, 195

11. Suppiej A, Tethered cord in patients with anorectal malformation. Pediatric Surg Int 2009;25(10):851-5

12. Tsuda T, Iwai N, Kimura O, Kubota Y, Ono S, Sasaki $Y$ : Bowel function after surgery of anorectal malformation in patients with tethered cord syndrome. Pediatr Surg Int 2007;23(12):1171-4

13. Golonka NR, Haga LJ, Keating RP: Routine MRI evaluation of low imperforate anus reveals unexpected high incidence of tethered spinal cord. J Pediatr Surg 2002;(7):966-969

14. Beek FJA Ultrasound of the lower spinal canal in infants.Utrecht:University of Utrecht, 1995.Thesis.

\section{How to cite this article?}

Chanchlani R, Agravat M, Agarwal V, Agarwal R, Rathore S. A study of Craniospinal Imaging in Patients with Anorectal Malformation. Int J Med Res Rev 2014;2(2):98-101. doi:10.17511/ijmrr.2014.i02.05 